\title{
Unsolved problems in the lowermost mantle
}

\author{
Kei Hirose, ${ }^{1}$ Shun-ichiro Karato, ${ }^{2}$ Vernon F. Cormier, ${ }^{3}$ John P. Brodholt, ${ }^{4}$ and \\ David A. Yuen ${ }^{5}$ \\ Received 6 January 2006; accepted 24 February 2006; published 31 March 2006.
}

[1] Many characteristics of $\mathrm{D}^{\prime \prime}$ layer may be attributed to the recently discovered $\mathrm{MgSiO}_{3}$ post-perovskite phase without chemical heterogeneities. They include a sharp discontinuity at the top of $\mathrm{D}^{\prime \prime}$, regional variation in seismic anisotropy, and a steep Clapeyron slope. However, some features remain unexplained. The seismically inferred velocity jump is too large in comparison to first principles calculations, and the sharpness of the discontinuity may require a chemical boundary. Chemical heterogeneity may play an important role in addition to the phase transformation from perovskite to postperovskite. Phase transformation and chemical heterogeneity and the attendant changes in physical properties, such as rheology and thermal conductivity, are likely to play competing roles in defining the dynamical stability of the $\mathrm{D}^{\prime \prime}$ layer. Revealing the relative roles between phase transition and chemical anomalies is an outstanding challenge in the study of the role of $\mathrm{D}^{\prime \prime}$ in thermal-chemical evolution of the Earth. Citation: Hirose, K., S. Karato, V. F. Cormier, J. P. Brodholt, and D. A. Yuen (2006), Unsolved problems in the lowermost mantle, Geophys. Res. Lett., 33, L12S01, doi:10.1029/ 2006GL025691.

\section{Introduction}

[2] Except near its bottom, the elastic structure of the lower mantle is nearly radially symmetric with lateral perturbations of $1 \%$ or less. Large anomalies in seismic velocities are observed in the deepest several hundred kilometers of the mantle (the $\mathrm{D}^{\prime \prime}$ layer). Since the origins of these anomalies were difficult to explain with the known properties of $\mathrm{MgSiO}_{3}$ perovskite (pv), the $\mathrm{D}^{\prime \prime}$ layer has long been the most enigmatic region inside the Earth. The recent discovery of the $\mathrm{MgSiO}_{3}$ post-perovskite (ppv) phase transition at $P-T$ conditions expected near the core-mantle boundary (CMB) has very important implications for the nature and dynamics of this mysterious hidden layer. Since the first announcement of the discovery of ppv in April 2004 [Murakami et al., 2004], rapid developments in

\footnotetext{
${ }^{1}$ Department of Earth and Planetary Sciences, Tokyo Institute of Technology, Tokyo, Japan.

${ }^{2}$ Department of Geology and Geophysics, Yale University, New Haven, Connecticut, USA. USA.

${ }^{3}$ Physics Department, University of Connecticut, Storrs, Connecticut,

${ }^{4}$ Department of Earth Sciences, University College London, London, UK.

${ }^{5}$ Department of Geology and Geophysics and Minnesota Supercomputing Institute, University of Minnesota, Minneapolis, Minnesota, USA.
}

Copyright 2006 by the American Geophysical Union. 0094-8276/06/2006GL025691 mineral physics, seismology and geodynamics have taken place, resulting in a genuine revolution in our understanding of the lowermost mantle. This special section is an outcome of the International Workshop on the "Post-perovskite phase transition in the Earth's deep mantle" that was held during 3-5 October 2005 in Tokyo (abstracts are found at the Visual Geosciences website).

[3] Many of the long-term enigmas in the lowermost mantle may be reconciled with this newly discovered ppv phase. However, simply by its very location, the $\mathrm{D}^{\prime \prime}$ layer is a thermal, chemical, and mechanical boundary separating a liquid iron core from the silicate rocky mantle, and one expects rich "geology" there. There should be a steep temperature gradient, which, depending on the heat flux from the core and the thermal conductivity of the materials, may be similar to or even greater than those in the lithosphere. Chemical heterogeneity is a natural consequence, and there should be large regionally varying strain-rates and correspondingly high but varying stress levels in that region. In view of the likely complexity in physical and chemical states, we summarize important unsolved problems in the lowermost mantle and future perspectives.

\section{Origin of $D^{\prime \prime}$ Discontinuity}

[4] Recognition of the $\mathrm{D}^{\prime \prime}$ seismic discontinuity began with the work of Lay and Helmberger [1983]. Body wave studies frequently find a sharp positive $\mathrm{S}$ velocity jump between 100 to $300-\mathrm{km}$ above the CMB. Murakami et al. [2004] showed that a phase transformation from $\mathrm{MgSiO}_{3}$ pv to ppv occurs at approximately $125 \mathrm{GPa}$ and $2500 \mathrm{~K}$ corresponding to $2700-\mathrm{km}$ depth. The cause of the $\mathrm{D}^{\prime \prime}$ discontinuity is likely this ppv phase transition, because the transition pressure corresponds to the depth of velocity increase. However, there has been extensive debate on the accuracy of the experimental pressure scale $(P-V-T$ equation of state). The phase transition boundary has been determined so far by using $\mathrm{Au}, \mathrm{MgO}$, and Pt pressure standards, in which the transition pressure differs by as much as $15 \mathrm{GPa}$ [Murakami et al., 2004; Ono and Oganov, 2005; Hirose et al., 2006]. A pressure scale reliable at such high $P-T$ conditions needs to be established. The phase boundary was also determined by theoretical calculations. These results are inconsistent by 10 to $20 \mathrm{GPa}$, mainly due to the difference between GGA and LDA calculations [Tsuchiya et al., 2004a; Oganov and Ono, 2004]. Consideration of compositional effects is also important. Hirose et al. [2006] demonstrated that the ppv phase transition in natural multi-component systems of pyrolitic mantle and MORB occurs at a pressure similar to that in pure $\mathrm{MgSiO}_{3}$. 
[5] The sense of $\mathrm{P}$ and $\mathrm{S}$ wave velocity jumps at the $\mathrm{D}^{\prime \prime}$ discontinuity are in general agreement with the predictions of mineral physics, the $\mathrm{P}$ jump being much smaller than the S jump [Tsuchiya et al., 2004b; Iitaka et al., 2004; Oganov and Ono, 2004; Stackhouse et al., 2005]. The PdP phase is less commonly observed perhaps due to this much smaller jump in $\mathrm{P}$ velocity. However, the magnitude of velocity jumps observed is sometimes up to $3 \%$ for both $\mathrm{P}$ and $\mathrm{S}$ waves [Wysession et al., 1998], which is much larger than that expected from mineral physics. It is still uncertain whether the large observed PdP amplitudes (compared to mineral physics predictions) are the result of anisotropy, focusing by topography enhanced by lateral temperature variations, or the effect of chemical variations associated with slab fragments.

[6] Seismology has shown that the $\mathrm{D}^{\prime \prime}$ velocity jump occurs in a width ranging from 50 to $70-\mathrm{km}$ [Young and Lay, 1987], which corresponds to the pressure interval of 3 to $4 \mathrm{GPa}$. Both experiments and theory show that pv and ppv coexist over a much wider pressure interval in the presence of $\mathrm{FeO}$ or $\mathrm{Al}_{2} \mathrm{O}_{3}$ [Mao et al., 2004; AkberKnutson et al., 2005]. The sharpness of the ppv phase transition in a multi-component natural system needs to be determined [Murakami et al., 2005; Ono and Oganov, 2005; Hirose et al., 2005]. On the seismology side, extracting the sharpness of the $\mathrm{D}^{\prime \prime}$ discontinuity requires careful analysis of the frequency dependence of reflections from broadband data, and has yet to be done with rigor even for the upper mantle phase transitions. Measuring this frequency dependence will require detailed modeling of all of the other frequency dependent effects of the waveform, including the source-time function and mantle attenuation and scattering, but is within the capabilities of current theory and observation.

[7] Theory first showed that the pv to ppv phase transition is a significantly large exothermic reaction [Tsuchiya et al., 2004a; Oganov and Ono, 2004]. This is generally consistent with the observations that an elevated $\mathrm{D}^{\prime \prime}$ discontinuity correlates with high velocities and evidence of deep slab penetration, and that the roots of large upwellings are associated with a depressed or absent $\mathrm{D}^{\prime \prime}$ discontinuity [e.g., Lay and Garnero, 2004]. In other words, the variations in the elevation of the $\mathrm{D}^{\prime \prime}$ discontinuity are roughly consistent with the Clapeyron slope of a ppv phase change, high temperature reducing its height, low temperature increasing its height. However, seismic imaging work suggests a much more complex character. In at least one location [Sun et al., 2006; Thomas et al., 2004], the discontinuity has been imaged as a step occurring over lateral dimensions less than $50-\mathrm{km}$. Can such a step be consistent with a realistic lateral temperature variation? Or, is it more consistent with chemically-distinct remnant slab fragments?

[8] A double-crossing of the ppv phase boundary in $\mathrm{D}^{\prime \prime}$ was suggested by Hernlund et al. [2005] from an image of a deeper negative velocity discontinuity following the positive discontinuity between 100 and $300-\mathrm{km}$ depth. The double-crossing can be induced by the strong temperature gradient in a thermal boundary layer, which moves the ppv phase region back into the pv field near CMB. Flores and Lay [2005], however, noted the difficulty in resolving this small waveform feature in the midst of contaminating arrivals arriving off-azimuth. If verified, the double-crossing in combination with the predictions of mineral physics can provide narrow bounds on the geotherm near the CMB in regions where it is observed.

\section{Is $D^{\prime \prime}$ Chemically Heterogeneous? \\ 3.1. Chemical and Phase Transformation Origin of Heterogeneity}

[9] A number of seismological studies have observed anomalies in the $\mathrm{D}^{\prime \prime}$ layer that cannot be explained by thermal perturbations alone [e.g., Karato and Karki, 2001]. These anomalies include the anti-correlation between anomalies in bulk-sound velocity and $\mathrm{S}$ wave velocity, and the anti-correlation between density and $\mathrm{S}$ wave velocity anomalies. Similarly the ratio of $\mathrm{S}$ to $\mathrm{P}$ wave velocity anomalies is higher than that expected for a thermal origin. For these reasons, Karato and Karki [2001] and Masters et al. [2000] argued that there must be chemical heterogeneity in the $\mathrm{D}^{\prime \prime}$ layer. However, some of these observations could well be explained by the phase transformation from $\mathrm{pv}$ to ppv phase [Iitaka et al., 2004; Oganov and Ono, 2004]. Since the degree and the nature of chemical heterogeneity in Earth's mantle are key to understanding the chemical evolution of this planet, it is critical to distinguish phenomena that may arise as a result of chemical heterogeneity from that caused by a phase transformation.

[10] Another aid in distinguishing chemical from thermal heterogeneity is studying the nature of density heterogeneities in the $\mathrm{D}^{\prime \prime}$ layer. If there is anti-correlation between density and velocity anomalies, then it must be due to chemical heterogeneity. Ishii and Tromp [1999] found an anti-correlation between density and velocity anomalies in the $\mathrm{D}^{\prime \prime}$ region from the analysis of free oscillations. However, Romanowicz [2001] suggested that the resolving power of free oscillations is weak and ambiguous in the lowermost mantle, with the sign of $\mathrm{d} \ln \mathrm{Vs} / \mathrm{d} \ln \rho$ being not well constrained. Based on waveform analysis, Garnero and Jeanloz [2000] provided some constraints on velocity and density anomalies in the $\mathrm{D}^{\prime \prime}$ layer. Similar analyses need to be conducted more extensively [Trampert et al., 2004].

\subsection{Possible Origins of Chemical Heterogeneities}

[11] Subduction of basaltic crust gives rise to a strong chemical heterogeneity in the mantle. Former basaltic crust is denser than the average mantle at any depths except between 660 and 720-km [Hirose et al., 2005]. The density contrast is about $3 \%$ at the base of the mantle. Geodynamical simulations have demonstrated that basaltic crust tends to segregate from the rest of slab at the CMB and accumulate to form a dense layer [Christensen and Hofmann, 1994]. However, the seismic evidence for a basaltic layer at the CMB has never been reported yet. We need to know the difference in elastic properties between peridotitic mantle and basaltic compositions. The basaltic component may be distinguished by the velocity change at the $\mathrm{D}^{\prime \prime}$ discontinuity. It includes similar amounts of $(\mathrm{Al}, \mathrm{Fe})$-bearing $\mathrm{MgSiO}_{3}$ pv and $\mathrm{SiO}_{2}$ phase, both of which undergo phase transitions near the $\mathrm{D}^{\prime \prime}$ discontinuity. These phase transitions have opposite effects on the seismic velocity change [Karki and Stixrude, 1999]. 
[12] Partial melting would also cause significant chemical differentiation at the base of the mantle, which is suggested by a number of seismic observations of an ultra-low velocity zone [e.g., Lay et al., 1998]. One would expect that the melting should have been more extensive in the past when the temperature was higher. However, the chemical consequences of such a melting process are not known. Very little has been reported on the partial melt composition above $50 \mathrm{GPa}$. Part of the geochemical variations found in plume-related magmas could be formed by melting at the CMB [Hirose et al., 2004]. We need to obtain more data on the element partitioning in the deep mantle. The discovery of the ppv phase has made this even harder to achieve since we cannot just extrapolate from low-pressure experiments on pv.

[13] A chemical reaction between the mantle and the liquid outer core may form a chemically distinct layer at the boundary. If the bottom of the mantle is partially molten, the chemical reaction should occur very effectively. Recent experiments by Takafuji et al. [2005] imply that the reaction causes depletion of iron in the mantle. $\mathrm{SiO}_{2}, \mathrm{FeSi}$, and $\mathrm{FeO}$ phases may also be formed at the boundary [Knittle and Jeanloz, 1991], which would contribute to chemical heterogeneities in $\mathrm{D}^{\prime \prime}$.

\section{Seismic Anisotropy and Flow Pattern in the $D^{\prime \prime}$ Layer}

[14] A large but heterogeneous distribution of seismic anisotropy is also an important characteristic of the deep lower mantle. Regional variations to commonly observed vertical-transverse isotropy might be explained by a complex distribution of partial melt and slab-related materials [Kendall and Silver, 1996; Wookey et al., 2005]. In contrast, Karato [1998] proposed that the anisotropy is mostly caused by lattice-preferred orientation ( $\mathrm{LPO})$ of $(\mathrm{Mg}, \mathrm{Fe}) \mathrm{O}$ and that the heterogeneous distribution of anisotropy is due to the distribution of stress and strain in the mechanical boundary layer. Until spatially dense seismic observations in $\mathrm{D}^{\prime \prime}$ can be collected, we cannot conclusively separate shape-preferred orientation from LPO as the origin of $\mathrm{D}^{\prime \prime}$ anisotropy.

[15] The ppv phase appears to have a relatively large elastic anisotropy [e.g., Tsuchiya et al., 2004b], although not as anisotropic as $(\mathrm{Mg}, \mathrm{Fe}) \mathrm{O}$. The anisotropy caused by deformation of ppv depends on the deformation mechanisms, particularly the slip systems. Since the ppv phase has rather unusual elastic properties such as the large elastic constant for shear along the layering plane, i.e., (010), the prediction of the slip system is not straightforward. Oganov et al. [2005] predicted the [110](110) slip system to be the dominant one, while Cordier et al. [2005] found practically the exact opposite. A third slip system of [100](010) has been suggested by Miyajima et al. [2005] based on TEM observations on $\mathrm{CaIrO}_{3}$, and is consistent with slip between the octahedral layers. Merkel et al. [2006] presented new experimental observations on LPO in $\mathrm{MgGeO}_{3} \mathrm{ppv}$ at room temperature, but the relevance of room temperature data to $\mathrm{D}^{\prime \prime}$ is highly uncertain because LPOs in many minerals are known to change with temperature. The determination of nature of LPO and resultant seismic anisotropy will help us map out the flow pattern of materials in the $\mathrm{D}^{\prime \prime}$ layer.

\section{Dynamics and Instability of $D^{\prime \prime}$ Layer}

[16] Both theory and experiments find the high positive Clapeyron slope for the ppv phase transformation $(+5$ to $+11 \mathrm{MPa} / \mathrm{K})[$ Tsuchiya et al., 2004a; Oganov and Ono, 2004; Ono and Oganov, 2005; Hirose et al., 2006], which is opposite in sign and 4 times the magnitude of the postspinel transformation. From the Clapeyron slope and the density contrast, one expects that the role of the pv to ppv transformation is similar to the role of a negative Clapeyron slope at the $660-\mathrm{km}$ discontinuity. The positive Clapeyron slope of the ppv transition can readily induce boundary layer instabilities at the $\mathrm{D}^{\prime \prime}$ layer [Nakagawa and Tackley, 2004]. Current tomographic images, however, show few but broad upwellings (two so-called "superplumes"). One must employ some radiative thermal conductivity to stabilize the highly unstable boundary layer in order for large stabilized upwellings to emerge [Matyska and Yuen, 2005, 2006]. Alternatively grain-size dependent rheology [Solomatov, 1996; Korenaga, 2005] may also help to induce the growth of large plumes from the highly unstable $\mathrm{D}^{\prime \prime}$ layer. As a result of the proximity of the ppv phase transition to the $\mathrm{CMB}$, new physical mechanism must now be invoked in order to model lower mantle dynamics.

[17] In terms of testing models, the resolution of seismic imaging needs to be improved. If the $\mathrm{D}^{\prime \prime}$ layer is highly unstable, we would expect a large number of small plumes. Some recent high-resolution tomographic studies show that these "super-plumes" indeed are composed of small plumes in some cases [Schubert et al., 2004]. Korenaga [2005] proposed a model to explain this incorporating the idea by Solomatov [1996] that viscosity of polycrystalline materials may increase as temperature goes up if grain-size is temperature dependent. Korenaga's [2005] model implies that a plume from the $\mathrm{D}^{\prime \prime}$ layer only entrains materials in the shallow portions. In contrast, a recent geochemical study of Hawaiian basalt suggests entrainment from the deep $D^{\prime \prime}$ layer [Bryce et al., 2005]. The dynamics of plume initiation in the $\mathrm{D}^{\prime \prime}$ layer is critical in understanding the significance of geochemical anomalies.

[18] Acknowledgments. The post-perovskite conference was sponsored by the COE project at the Tokyo Institute of Technology, the CSEDI program of the NSF, and the Vlab of the University of Minnesota. Comments by D. Frost on the manuscript were helpful.

\section{References}

Akber-Knutson, S., G. Steinle-Neumann, and P. D. Asimow (2005), Effect of $\mathrm{Al}$ on the sharpness of the $\mathrm{MgSiO}_{3}$ perovskite to post-perovskite phase transition, Geophys. Res. Lett., 32, L14303, doi:10.1029/2005GL023192.

Bryce, J. G., D. J. DePaolo, and J. C. Lassiter (2005), Geochemical structure of the Hawaii plume: $\mathrm{Sr}, \mathrm{Nd}$, and Os isotopes in the $2.8 \mathrm{~km}$ HSDP-2 section of Mauna Kea volcano, Geochem. Geophys. Geosyst., 6, Q09G18, doi:10.1029/2004GC000809.

Christensen, U. R., and A. W. Hofmann (1994), Segregation of subducted oceanic crust in the convecting mantle, J. Geophys. Res., 99, 19,86719,884 .

Cordier, P., P. Carrez, D. Ferre, D. Mainprice, and A. Tommasi (2005), Plastic anisotropy of $\mathrm{MgSiO}_{3}$ post-perovskite: Implications for crystallographic preferred orientation and seismic anisotropy in the $\mathrm{D}^{\prime \prime}$ Layer, Eos Trans. $A G U, 86(52)$, Fall Meet. Suppl., Abstract MR23B-0055.

Flores, C., and T. Lay (2005), The trouble with seeing double, Geophys. Res. Lett., 32, L24305, doi:10.1029/2005GL024366. 
Garnero, E. J., and R. Jeanloz (2000), Fuzzy patches on the Earth's coremantle boundary?, Geophys. Res. Lett., 27, 2777-2780.

Hernlund, J., C. Thomas, and P. J. Tackley (2005), A doubling of the postperovskite phase boundary and structure of the Earth's lowermost mantle, Nature, 434, 882-886.

Hirose, K., N. Shimizu, W. van Westrenen, and Y. Fei (2004), Trace element partitioning in Earth's lower mantle and implications for the geochemical consequences of partial melting at the core-mantle boundary, Phys. Earth Planet. Inter., 146, 249-260.

Hirose, K., N. Takafuji, N. Sata, and Y. Ohishi (2005), Phase transition and density of subducted MORB crust in the lower mantle, Earth Planet. Sci. Lett., 237, 239-251.

Hirose, K., R. Sinmyo, N. Sata, and Y. Ohishi (2006), Determination of post-perovskite phase transition boundary in $\mathrm{MgSiO}_{3}$ using $\mathrm{Au}$ and $\mathrm{MgO}$ internal pressure standards, Geophys. Res. Lett., 33, L01310, doi:10.1029/2005GL024468.

Iitaka, T., K. Hirose, K. Kawamura, and M. Murakami (2004), The elasticity of the $\mathrm{MgSiO}_{3}$ post-perovskite phase in the Earth's lowermost mantle, Nature, 430, 442-445.

Ishii, M., and J. Tromp (1999), Normal-mode and free-air gravity constraints on lateral variations in velocity and density of Earth's mantle, Science, 285, 1231-1236.

Karato, S. (1998), Seismic anisotropy in the deep mantle, boundary layers and geometry of mantle convection, Pure Appl. Geophys., 151, 565-587.

Karato, S., and B. B. Karki (2001), Origin of lateral heterogeneity of seismic wave velocities and density in Earth's deep mantle, J. Geophys. Res., 106, 21,771-21,783.

Karki, B. B., and L. Stixrude (1999), Seismic velocities of major silicate and oxide phases of the lower mantle, J. Geophys. Res., 104, 13,02513,034 .

Kendall, J.-M., and P. G. Silver (1996), Constraints from seismic anisotropy on the nature of the lowermost mantle, Nature, 381, 409-412.

Knittle, E., and R. Jeanloz (1991), Earth's core-mantle boundary: Results of experiments at high pressures and temperatures, Science, 251, 14381443.

Korenaga, J. (2005), Firm mantle plumes and the nature of the core-mantle region, Earth Planet. Sci. Lett., 232, 29-37.

Lay, T., and E. J. Garnero (2004), Core-mantle boundary structures and processes, in The State of the Planet: Frontiers and Challenges in Geophysics, Geophys. Monogr. Ser., vol. 150, edited by R. S. J. Sparks and C. J. Hawkesworth, pp. 25-42, AGU, Washington, D. C.

Lay, T., and D. V. Helmberger (1983), A lower mantle S-wave triplication and the shear velocity structure of $\mathrm{D}^{\prime \prime}$, Geophys. J. R. Astron. Soc., 75, $799-838$.

Lay, T., Q. Williams, and E. Garnero (1998), The core-mantle boundary layer and deep mantle dynamics, Nature, 392, 461-468.

Mao, W. L., G. Shen, V. B. Prakapenka, Y. Meng, A. J. Cambell, D. Heinz, J. Shu, R. J. Hemley, and H. K. Mao (2004), Ferromagnesian postperovskite silicates in the $\mathrm{D}^{\prime \prime}$ layer of the earth, Proc. Natl. Acad. Sci. U. S. A., 101, 15,867-15,869.

Masters, G., G. Laske, H. Bolton, and A. M. Dziewonski (2000), The relative behavior of shear velocity, bulk sound speed, and compressional velocity in the mantle: Implications for chemical and thermal structure, in Earth's Deep Interior: Mineral Physics and Tomography From the Atomic to the Global Scale, Geophys. Monogr. Ser., vol. 117, edited by S. Karato et al., pp. 63-87, AGU, Washington, D. C.

Matyska, C., and D. A. Yuen (2005), The importance of radiative heat transfer on superplumes in the lower mantle with the new post-perovskite phase change, Earth Planet. Sci. Lett., 234, 71-81.

Matyska, C., and D. A. Yuen (2006), Lower mantle dynamics with the postperovskite phase change, radiative thermal conductivity, temperature- and depth-dependent viscosity, Phys. Earth Planet. Inter., 154, 196-207.

Merkel, S., A. Kubo, L. Miyagi, S. Speziale, T. S. Duffy, H.-K. Mao, and H.-R. Wenk (2006), Plastic deformation of $\mathrm{MgGeO}_{3}$ post-perovskite at lower mantle pressures, Science, 311, 644-646.

Miyajima, N., K. Ohgushi, M. Ichihara, T. Yagi, D. J. Frost, and D. C. Rubie (2005), Crystal morphology and dislocation textures of the $\mathrm{CaIrO}_{3}$ phase-TEM study of an analogue of the post-perovskite phase, Layer, Eos Trans. $A G U, 86(52)$, Fall Meet. Suppl., Abstract MR23B-0069.
Murakami, M., K. Hirose, K. Kawamura, N. Sata, and Y. Ohishi (2004), Post-perovskite phase transition in $\mathrm{MgSiO}_{3}$, Science, 304, 855-858.

Murakami, M., K. Hirose, N. Sata, and Y. Ohishi (2005), Post-perovskite phase transition and crystal chemistry in the pyrolitic lowermost mantle, Geophys. Res. Lett., 32, L03304, doi:10.1029/2004GL021956.

Nakagawa, T., and P. J. Tackley (2004), Effects of a perovskite-post perovskite phase change near core-mantle boundary in compressible mantle convection, Geophys. Res. Lett., 31, L16611, doi:10.1029/ 2004GL020648.

Oganov, A. R., and S. Ono (2004), Theoretical and experimental evidence for a post-perovskite phase of $\mathrm{MgSiO}_{3}$ in Earth's $\mathrm{D}^{\prime \prime}$ layer, Nature, 430, $445-448$.

Oganov, A. R., R. Martonak, A. Laio, P. Raiteri, and M. Parrinello (2005), Anisotropy of Earth's D" layer and stacking faults in the $\mathrm{MgSiO}_{3}$ postperovskite phase, Nature, 438, 1142-1144.

Ono, S., and A. R. Oganov (2005), In situ observations of phase transition between perovskite and $\mathrm{CaIrO}_{3}$-type phase in $\mathrm{MgSiO}_{3}$ and pyrolitic mantle composition, Earth Planet. Sci. Lett, 236, 914-932.

Romanowicz, B. (2001), Can we resolve 3D density heterogeneity in the lower mantle?, Geophys. Res. Lett., 28, 1107-1110.

Schubert, G., G. Masters, P. Olsen, and P. Tackley (2004), Superplumes or plume clusters?, Phys. Earth Planet. Inter., 146, 147-162.

Solomatov, V. (1996), Can hotter mantle have a larger viscosity?, Geophys. Res. Lett., 23, 937-940.

Stackhouse, S., J. P. Brodholt, J. Wookey, J.-M. Kendall, and G. D. Price (2005), The effect of temperature on the seismic anisotropy of the perovskite and post-perovskite polymorphs of $\mathrm{MgSiO}_{3}$, Earth Planet. Sci. Lett., 230, $1-10$.

Sun, D., T.-R. A. Song, and D. Helmberger (2006), Complexity of $\mathrm{D}^{\prime \prime}$ in the presence of slab-debris and phase changes, Geophys. Res. Lett., 33, L12S07, doi:10.1029/2005GL025384.

Takafuji, N., K. Hirose, M. Mitome, and Y. Bando (2005), Solubilities of O and $\mathrm{Si}$ in liquid iron in equilibrium with $(\mathrm{Mg}, \mathrm{Fe}) \mathrm{SiO}_{3}$ perovskite and the light elements in the core, Geophys. Res. Lett., 32, L06313, doi:10.1029/ 2005 GL022773.

Thomas, C., E. J. Garnero, and T. Lay (2004), High resolution imaging of lowermost mantle structure under the Cocos plate, J. Geophys. Res., 109, B08307, doi:10.1029/2004JB003013.

Trampert, J., F. Deschamps, J. Resovsky, and D. Yuen (2004), Probabilistic tomography maps chemical heterogeneities throughout the lower mantle, Science, 306, 853-856.

Tsuchiya, T., J. Tsuchiya, K. Umemoto, and R. M. Wentzcovitch (2004a), Phase transition in $\mathrm{MgSiO}_{3}$ perovskite in the Earth's lower mantle, Earth Planet. Sci. Lett., 224, 241-248.

Tsuchiya, T., J. Tsuchiya, K. Umemoto, and R. M. Wentzcovitch (2004b), Elasticity of post-perovskite $\mathrm{MgSiO}_{3}$, Geophys. Res. Lett., 31, L14603, doi:10.1029/2004GL020278.

Wookey, J., J.-M. Kendall, and G. Rumpker (2005), Lowermost mantle anisotropy beneath the North Pacific from differential S-ScS splitting, Geophys. J. Int., 161, 829-838.

Wysession, M. E., T. Lay, J. Revenaugh, Q. Williams, E. Garnero, R. Jeanloz, and L. Kellogg (1998), The $\mathrm{D}^{\prime \prime}$ discontinuity and its implications, in The Core-Mantle Boundary Region, Geodyn. Ser, vol. 28, edited by M. Gurnis et al., pp. 273-297, AGU, Washington, D. C.

Young, C. J., and T. Lay (1987), Evidence for a shear velocity discontinuity in the lower mantle beneath India and the Indian Ocean, Phys. Earth Planet. Inter., 49, 37-53.

J. P. Brodholt, Department of Earth Sciences, University College London, London WC1E 6BT, UK.

V. F. Cormier, Physics Department, University of Connecticut, Storrs, CT 06269-2045, USA.

K. Hirose, Department of Earth and Planetary Sciences, Tokyo Institute of Technology, Tokyo 152-8551, Japan. (kei@geo.titech.ac.jp)

S. Karato, Department of Geology and Geophysics, Yale University, New Haven, CT 06520, USA.

D. A. Yuen, Department of Geology and Geophysics, University of Minnesota, Minneapolis, MN 55415-1227, USA. 